\title{
Influencing memory for people and their actions
}

\author{
DAVID G. MILLER and ELIZABETH F. LOFTUS \\ University of Washington, Seattle, Washington 98195
}

\begin{abstract}
In two experiments subjects saw slides of people behaving. Afterward some subjects were asked questions suggesting that a particular person had done something that was actually done by someone else. The effect of these leading questions was to increase the likelihood that a person was recalled as having committed an act that he did not commit.
\end{abstract}

When a person witnesses a second person engaged in some activity, certain bits of information become recorded in the memory of the witness. When later asked about the incident, the witness must reconstruct the incident that was observed. The reconstruction can be strongly influenced by new information that is received after the incident. It has been argued that this new information can actually alter or distort the original memory, an argument which receives support from numerous studies in which long-term recollections about a complex event were influenced by leading questions asked immediately after the event (Loftus \& Palmer, 1974; Loftus, 1975).

Specifically, in one study (Loftus, 1975, Experiment 3) subjects viewed a video tape of an automobile accident and then answered questions about the accident. Half of the subjects were asked "How fast was the white sports car going when it passed the barn while traveling along the country road?," while the remaining subjects were asked "How fast was the white sports car going while traveling along the country road?" All subjects returned 1 week later and were asked, "Did you see a barn?" In fact, no subject could have seen a barn, since none existed. The subjects who heard the question presupposing the existence of a barn were over six times as likely to say that they had seen one. As an explanation for this phenomenon, it was argued that the subjects altered their memorial representation corresponding to the accident by integrating a barn into it; subsequently, they "saw" a barn that they themselves constructed.

Unlike the accident witness, a witness to a crime is often asked to remember the person who committed the crime. Here the phenomenon of "unconscious transference" is important. Unconscious transference occurs when a person seen committing one act is confused with or recalled as the person seen committing a second act. A real-life example of this phenomenon is discussed in Wall $(1965$, p. 120). A ticket agent in

This research was supported in part by a grant from the Department of Transportation. The authors thank Steve Woods for his critical reading of the manuscript. Reprint requests should be sent to Elizabeth Loftus, University Hall, Harvard University, Cambridge, Massachusetts 02138. a railroad station was held up at gun point and subsequently the agent recognized a sailor in a line-up as the culprit. The sailor had an iron-clad alibi, however, and was eventually released from custody. The ticket agent, who was later interviewed in an attempt to determine why he had misidentified the sailor, said that when he saw the sailor in the line-up, his face looked familiar. This was not surprising, since the sailor's base was near the railroad station and on three occasions prior to the robbery he had purchased tickets from this agent. It appears, then, that the ticket agent mistakenly assumed that the familiarity related back to the robbery when it undoubtedly related back to the three times the sailor bought train tickets. This is an example of unconscious transference-the face of the person seen buying tickets was transferred to or integrated with the act of armed robbery, an act that was actually committed by someone else.

The present research was designed to answer this question: When a witness sees a number of people committing different acts, to what extent can leading questions increase the likelihood that a person seen performing one act will be recalled as the person seen performing a different act?

\section{EXPERIMENT I}

\section{Method}

Twenty-six students at the University of Washington volunteered to participate as subjects in exchange for course credit. The experiment was divided into three phases. First, the subject saw a series of 20 slides presented for $3 \mathrm{sec}$ each. Each slide depicted one of five persons (models) engaged in one of four different activities. The models were four women and one man, all of college age. The models were photographed performing activities such as blowing up a balloon, reading a book, and working a jigsaw puzzle. Each model was seen four times, doing four different things. Two models were never depicted doing the same thing. The experiment was counterbalanced such that across subjects each of the five models was seen performing some particular act (e.g., reading a book) approximately equally often.

After the 20 slides had been presented, the subject performed a 10-min filler activity (reading an unrelated magazine article). In the second phase of the experiment, the subject was asked a series of questions about the slides. The procedure was as follows. A slide showing one of the models in a standing position was displayed and a question was simultaneously asked. For example, a slide of the man was displayed and the question 
"What color was the balloon he was blowing up?" was asked. In 16 cases the question was appropriate to the model (i.e., the man had actually been seen blowing up a balloon). In four cases the question referred to a behavior performed by one of the other four models (i.e., the balloon had actually been blown up by one of the four women).

In the third and final phase of the experiment, the subject was shown 20 slides and asked to say whether each one had been presented previously. Six of the slides were ones that had been seen previously, and six were slides that were very different from the previous set (e.g., a model holding a cat). The remaining eight slides depicted one of the five models doing something that had previously been done by one of the other models. Questions asked during Phase 2 suggested to the subject that he had seen four of these slides. For the other four, there had been no suggestion.

\section{Results}

The proportion of "yes" responses to each of the four types of recognition slides was tabulated for each subject. If the slide had been seen previously, a mean of $88 \%$ of the responses were correctly "yes." If the slide had not been seen before and was unrelated, a mean of $3 \%$ of the responses were incorrectly "yes." If a leading question asked during Phase 2 had falsely suggested that a model seen in Phase 3 performed the behavior on the slide, subjects falsely recognized the slide $69 \%$ of the time. If there had been no suggestion, subjects falsely recognized the slide $48 \%$ of the time, $\mathrm{t}(25)=4.62, \mathrm{p}<.001$. Thus, by asking a witness a leading question such as "What color was the balloon he was blowing up?" and indicating a specific person, it is possible to induce the witness to testify later that he had seen that person doing something whether or not it was actually true.

\section{EXPERIMENT II}

In Experiment I a subject saw models perform 20 different unrelated activities. The recognition task was reasonably difficult; even when no suggestion occurred, subjects falsely accused a model of committing another model's behavior nearly half of the time. In Experiment II subjects saw six models, each doing one thing. The behaviors formed a realistic sequence. Again, the purpose of the experiment was to determine the extent to which a leading question could induce a witness to recall a person seen doing one thing as the person who actually did something else.

\section{Method}

Procedure. The subjects were 100 students at the University of Washington. Each subject heard, via tape recorder, a story concerning six college students. The introduction of each character was accompanied by a slide of that character. The characters were all white males with medium-length brown hair and no glasses.

Each subject heard the following story: "Of Jim Fisher, the valedictorian of his class, it is commonly said that he gives a misleading initial impression. Many of his classmates find him, on first acquaintance, to be a quiet, somewhat distant person who is more measuring than gregarious. 'It is often said of Jim that he is aloof and calculating,' says Howard Leland, who is a long-time friend of Fisher's. Some people resent this. In fact, one day last week several of the guys on the debate team, including Robert Dirks, initiated an argument with Fisher, for seemingly no reason at all. They were all probably in a rotten mood and wanted someone to pick on. Steve Kent was the worst of the bunch; he went too far this time. When Fisher started yelling back, Kent picked up a heavy paperweight and threw it at Fisher, hitting him on the side of the head. Fisher fell over. Two people had witnessed the whole event. Sam Tappin ran to the nearest telephone to call an ambulance. He had trouble speaking coherently because he was so nervous about what had happened. David McCoy rushed over to help Fisher. The rest of the guys had already run away."

As each character was introduced, a slide of that person was displayed for approximately $2 \mathrm{sec}$. Fisher was shown walking by an auditorium; Howard Leland was shown driving by the auditorium; Robert Dirks was shown walking up to the auditorium, wearing a small brown hat; Steve Kent was shown with a paperweight in his hand; etc. After the subject heard the story and saw the slides, he participated in a filler activity of reading an unrelated magazine story and answering several questions about it. This took approximately $40 \mathrm{~min}$. The subject was then asked 10 questions about the original story, one of which was critical. Half of the subjects were asked, "After the guy with the hat threw the paperweight at Fisher, did he run away?" and the other half were asked, "After the guy threw the paperweight at Fisher, did he run away?"

The subject returned 3 days later and was shown six fullface photographs-one of each of the characters-and asked whether the person who had thrown the paperweight in the original story was among the set of six and, if so, which one he was.

Design. All subjects heard the same story, but different groups of subjects saw different people committing the six acts. For example, a given person might have represented Steve Kent, the culprit, for one group of subjects and represented Robert Dirks, the man with the hat, for another group of subjects. During the final phase of the experiment, all subjects saw a set of six photographs for identification purposes. The person who had represented Robert Dirks was the only person to wear a hat.

In sum, each subject listened to a story which was accompanied by slides of characters acting various roles in the story. After a filler activity, half of the subjects were asked a question that falsely implied that the person with the hat committed the crime; the other half were not. After 3 days, the subjects attempted to identify the criminal in the story from a set of six faces presented to them.

\section{Results}

Of the 50 subjects who had been asked a question implying that the person with the hat committed the crime, 29 made a correct identification, 12 chose the man with the hat, and 9 chose one of the other four characters. Of the 50 subjects who had not been asked the leading question, 40 made a correct identification, 3 chose the man with the hat, and 7 chose one of the other four characters. Thus, the leading question significantly affected the distribution of choices, $\chi^{2}(2)=7.42, p<.025$. Specifically, the occurrence of only one type of error was increased.

\section{DISCUSSION}

In two experiments, witnesses saw a number of people doing different things and were then asked leading questions which suggested that a person had done something that was actually done by someone else. The effect of these leading questions was to increase the likelihood that a person was recalled as having committed an act he did not commit. 
These experiments provide additional support for the view that information provided subsequent to an initial experience (in this case, information provided via leading questions) can change the memory for that experience. In previous research it was shown that new information could alter a judgment about the speed of vehicles and the severity of an automobile accident (Loftus \& Palmer, 1974), could raise or lower the estimate of the number of people involved in a classroom disruption (Loftus, 1975, Experiment 2), and could increase the likelihood that nonexistent objects would be "recalled" (Loftus, 1975, Experiments 3 and 4). In the present research, suggestive questions induced a witness to accuse a person of doing something that he had not done. This result is not surprising if one accepts the constructive nature of human memory; the person is familiar, the behavior is familiar, and the witness himself constructs the combination so that it is now familiar.

\section{REFERENCES}

LofTus, E. F. Leading questions and the eyewitness report. Cognitive Psychology, 1975, in press.

Loftus, E. F., \& Palmer, J. C. Reconstruction of automobile destruction: An example of the interaction between language and memory. Journal of Verbal Learning and Verbal Behavior. 1974, 13. 585-589.

W ALL, P. M. Eye-witness identification in criminal cases. Springfield, Ill: Charles C Thomas, 1965.

(Received for publication August 22, 1975.) 